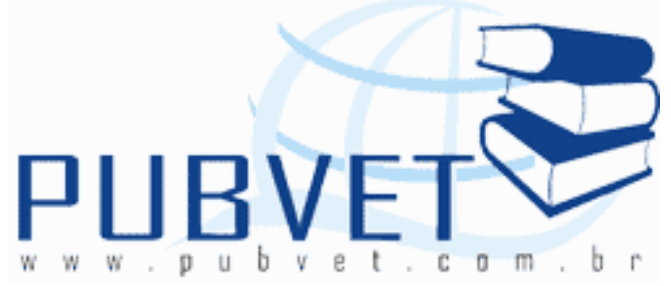

PUBVET, Publicações em Medicina Veterinária e Zootecnia.

\title{
Avicultura de postura: um estudo de caso através da análise de filière
}

André Mauro Santos de Espíndola ${ }^{1}$, Leonardo Roth ${ }^{2}$, Michele Otobelli Bertéli ${ }^{3}$, Guilherme Cunha Malafaia ${ }^{4}$

${ }^{1}$ Mestrando em Administração pela Universidade de Caxias do Sul. Licenciatura em Matemática pela Universidade Federal do Rio Grande do Sul - UFRGS. e-mail: amsespin@ucs.br

${ }^{2}$ Mestrando em Administração pela Universidade de Caxias do Sul. Bacharel em Administração de Empresas - UCS. e-mail: Iroth@ucs.br

${ }^{3}$ Mestranda em Administração pela Universidade de Caxias do Sul. Bacharel em Engenharia de Produção pela Universidade de Caxias do Sul - UCS. e-mail: micheleberteli@gmail.com

${ }^{4}$ Doutor em Agronegócios - UFRGS. Professor do Programa de Pós-graduação em Administração - Universidade de Caxias do Sul - UCS. e-mail: gcmalafa@ucs.br

\section{Resumo}

Este trabalho buscou identificar os pontos fortes e fracos de uma empresa do Rio Grande do Sul, fornecedora de aves para avicultura de postura, através da análise filière. O método de pesquisa utilizado foi classificado como sendo uma pesquisa de abordagem qualitativa, com objetivo descritivo, assumindo a forma de estudo de caso. Uma entrevista em profundidade foi realizada no dia 20 de janeiro de 2012, usando como base um roteiro estruturado já validado. 
Através da análise efetuada e das pesquisas bibliográficas realizadas, foi possível desenhar a cadeia produtiva da avicultura de postura, identificando a localização da empresa objeto do estudo e fazer a análise filière. Os resultados mostraram que o conhecimento da cadeia produtiva da avicultura de postura, a identificação dos pontos fortes e fracos, assim como dos gargalos da empresa estudada é importante para aumentar sua capacidade produtiva e a qualidade dos produtos fornecidos, suprindo, dessa forma, as demandas de um mercado em crescimento.

Palavras-chave: Cadeia Produtiva. Filière. Avicultura de Postura.

\title{
Poultry posture: a case study by analyzing filière
}

\begin{abstract}
This study aimed to identify the strengths and weaknesses of a company from Rio Grande do Sul, a supplier of poultry birds to posture by analyzing filière. The research method used was classified as a qualitative study with a descriptive purpose, in the form of case study. An in-depth interview was held on January 20, 2012, using a structured questionnaire based on previously validated. Through the analysis performed and conducted literature searches, it was possible to draw the poultry production chain of posture, identifying the location of the business object of study and do the filière analysis. The results showed that knowledge of the production chain of poultry posture, identifying the strengths and weaknesses as well as the bottlenecks of the company it is important to increase its production capacity and quality of products supplied, supplying the demands of a growing market.
\end{abstract}

Keywords: Production Chain. Filière. Poultry Posture.

\section{INTRODUÇÃO}

O estudo das estruturas de arranjos produtivos é importante para uma crescente qualificação e aprimoramento da gestão da produção. Somente 
ESPÍNDOLA, A.M.S. et al. Avicultura de postura: um estudo de caso através da análise de filière. PUBVET, Londrina, V. 7, N. 3, Ed. 226, Art. 1500, 2013.

através do conhecimento mais amplo das estruturas é possível aprimorá-las, tornando-as mais competitivas.

Segundo a FAO (Food and Agriculture Organization) o consumo mundial de ovos vem crescendo nas últimas décadas. Comparando a produção dos anos de 1970 com 2007, respectivamente, de 20 milhões e 60 milhões de toneladas, pode-se verificar um crescimento de $200 \%$ no período, ou seja, um crescimento médio de $5,26 \%$ ao ano. Peritos da comissão internacional do ovo estimam que se a taxa de crescimento continuar próxima de constante, o volume de produção de ovos, nos próximos anos, pode ser maior que o da carne bovina (FAO, 2010).

No Brasil, o crescimento também é verificado ao se comparar a produção total de 2003 com a de 2010. A taxa de crescimento no período foi de 39,34\%, com aumento médio de $4,91 \%$ ao ano. O consumo per capto é outro indicador das possibilidades de crescimento do consumo mundial e nacional. Em países como China e México, o consumo, no ano de 2007 foi respectivamente de 340 e 351 ovos (FAO, 2010, p. 49). Ao comparar com o consumo brasileiro, de 132 ovos per capto no ano de 2007, constata-se a possibilidade de crescimento do consumo nacional. O consumo per capto brasileiro no ano de 2010 foi de 148,85 ovos, que representa um incremento de $12,76 \%$, confirmado a potencial expansão do mercado (UBABEF, 2010, p. 53). Este consumo, segundo a FAO, tem uma ligação direta com o crescimento da população e do poder de compra da nova classe média ${ }^{1}$.

Diante disto, justifica-se a importância de identificar os pontos fortes e fracos de uma empresa fornecedora de aves para avicultura de postura, objetivo deste trabalho, através da análise filière, pois, com estes estudos, formaliza-se o conhecimento existente e sugere-se melhorias para que a cadeia seja aprimorada, suprindo as necessidades do mercado em expansão.

Desta forma, o artigo apresenta um estudo de caso realizado numa empresa pertencente à cadeia produtiva da avicultura de postura, com sede

\footnotetext{
${ }^{1}$ Nova classe média: indivíduos que possuem uma renda domiciliar total compreendida no intervalo entre 1064 reais a 4591 reais por mês (NERI, 2008, p. 28).
} 
administrativa no município de Porto Alegre. Seu principal produto é o pinto de um dia, distribuído em todo território nacional com exportação regular para os continentes americano e africano.

\section{REVISÃO DA LITERATURA}

\subsection{Cadeia produtiva}

Durante a década de 60 desenvolveu-se no âmbito da escola industrial francesa a noção de análise de filière. Este conceito não foi desenvolvido especificamente para estudar a problemática agroindustrial, mas foi entre os economistas agrícolas e pesquisadores ligados aos setores rural e agroindustrial que se encontrou os principais defensores do tema (BATALHA, 2001). Estas escolas enfatizaram um processo mais dinâmico de pesquisa e ampliaram o conjunto de variáveis dependentes para abranger não apenas a eficiência, mas também medidas políticas (SHAFFER, 1973).

Conforme Batalha et al (1997), a palavra filière foi traduzida para o português como Cadeia Produtiva e, no caso do setor agroindustrial, surgiu à metodologia da Cadeia Produtiva Agroindustrial (CPA). Uma CPA é definida a partir da identificação do produto final, sendo encadeado de jusante a montante pelas várias operações técnicas, comerciais e logísticas necessárias à sua produção. A diferença principal em relação à abordagem da filière está na importância atribuída ao consumidor final como agente dinamizador da cadeia. A análise de filière privilegia o mercado final em direção à matéria-prima básica para a sua produção, enquanto que a CPA parte da matéria-prima em direção ao cliente final. De qualquer forma, os dois principais aspectos destacados pelas duas metodologias são o caráter meso-analítico e sistêmico dos estudos de cadeias produtivas agroindustriais (BATALHA et al, 1997).

Como o interesse na agroindustrialização cresceu, aumentou a atenção dada para a abordagem de estrutura verticalizada de mercado entre os especialistas internacionais de desenvolvimento agrícola, como um público de 
metodologia de pesquisa orientado para uma política aplicável de diagnóstico (BOOMGARD et al, 1991).

A análise de filière é uma análise de como as lógicas dos agentes, dos produtos e dos mercados se articulam entre si para estruturar um sistema. Lauret (1983) opina que a filière é uma abstração, uma representação de uma parte da realidade econômica visando a mensurar, a compreender, a explicar a estrutura e o funcionamento de certo campo. A noção de filière deve comportar três elementos constituídos, tais como uma sucessão de operações de transformações ligadas entre si por encadeamentos de técnicas e tecnologias; um conjunto de relações comerciais e financeiras estabelecidas entre os estágios de transformação; e um conjunto organizado de interrelações (BANDT, 1982; MORVAN, 1985; FLORIOT, 1985). Neste mesmo sentido, Morvan (1988), coloca que a cadeia de produção é uma sucessão de operações de transformação dissociáveis, capazes de ser separadas e ligadas entre si por um encadeamento técnico; um conjunto de relações comerciais e financeiras que estabelecem, entre todos os estados de transformação, um fluxo de troca entre fornecedores e clientes; e, um conjunto de ações econômicas que presidem a valoração dos meios de produção e asseguram a articulação das operações.

A preocupação com a coordenação das cadeias de produção agroindustriais passa a ser um dos desafios mais importantes para os tomadores de decisões que atuam no agronegócio. Assim sendo, essas cadeias aparecem como um instrumento valioso, tendo em vista que a descoberta de novas tecnologias poderá necessariamente modificar a natureza dos produtos e, em consequência, a estrutura dos mercados (OASHI, 1999).

\subsection{Avicultura de postura}

Esse ramo da atividade agroindustrial subdivide-se em avicultura de postura, voltada para a produção de ovos e avicultura de corte, com foco no 
consumo da carne e seus derivados. As aves de corte, a partir do nascimento, estão prontas para o abate entre 35 e 48 dias de vida, enquanto que as aves de postura estão prontas para a produção de ovos entre 50 e 60 semanas de vida, conforme os estudos de Pedrozo e Francisco (2004). As linhagens ou tipos de aves principais para a postura são Hy-Line, Isa Babcock, Lohmann, Hisex, Nick Chick e Embrapa.

No início da avicultura de postura brasileira, os criadores concentravam esforços no manejo de forma cooperativada, com foco no fornecimento de ração e na comercialização dos ovos (MIZUMOTO, 1996). Com o crescimento populacional, o desenvolvimento dos sistemas de criação de aves de postura orientou a produção para a otimização dos custos de instalação e consumo de energia (SOBRINHO; FONSECA, 2007). Esse manejo, através da industrialização, necessitou reinventar as práticas de trabalho seguindo dez programas sugeridos pela FAO: (1) conservação do solo; (2) uso da água; (3) produção vegetal; (4) produção animal; (5) proteção ambiental; (6) proteção animal (bem-estar animal); (7) manejo e processamento; (8) higiene e saúde humana; (9) eliminação de resíduos e conservação de energia; e (10) proteção à fauna selvagem. Muitas dessas práticas, comuns as atividades agropecuárias, são os estágios iniciais para sistemas e melhorias com foco sustentável nas cadeias produtivas (FAO, 2010).

Sobrinho e Fonseca (2007) afirmam ainda, que nos últimos 30 anos essas técnicas demonstraram a necessidade das especificações da FAO para o manejo otimizado que, ao contrário de outras espécies animais, o manejo é individualizado. Afirmam ainda que os aviários são fábricas vivas de produção de ovos e que, os controles e medições periódicas da evolução da produção, temperatura das salas, consumo de água e alimentos tornam-se indispensáveis, sendo uma atividade viável economicamente e passível de realização em pequenas e médias propriedades.

O estudo conduzido por Sossidou e Elson (2009) também aborda os aspectos da relação existente entre o bem-estar das galinhas com a qualidade dos ovos. Para os autores, a preocupação pública em melhorar o bem-estar 
das galinhas poedeiras ocorre em função de ser uma área potencial que agrega valor para os produtores, varejistas, transformadores, fabricantes e cooperativistas. Em contrapartida, a pesquisa realizada por Manning, Baines e Chadd (2007) demonstrou que os produtores de aves estão principalmente em conformidade com normas de garantia da fazenda a fim de manter o acesso ao mercado. Em geral, eles não têm visto até agora nenhum outro benefício financeiro ou organizacional de conformidade que não seja continuar a fornecer aos seus clientes de varejo.

\subsection{Produção e consumo de ovos}

Enquanto o consumo total de ovos e o consumo de ovos per capto continuam crescendo em qualquer lugar, nos países em desenvolvimento, o ganho é feito a partir de um aumento nas compras de ovos em casca. Por outro lado, para muitas economias desenvolvidas, o ganho reflete um aumento na compra de produtos que possuem ovo na sua composição (FAO, 2010). Os estudos conduzidos na melhoria da qualidade dos ovos e bem-estar das galinhas também impactaram no crescimento do consumo mundial de ovos, conforme demonstrado no Quadro 1.

Quadro 1 - Consumo mundial de ovos - 10 primeiros mais o Brasil

\begin{tabular}{|l|c|c|c|c|c|c|c|}
\hline \multicolumn{1}{|c|}{ País } & $\begin{array}{c}\text { População } \\
\text { (milhões) }\end{array}$ & \multicolumn{2}{c|}{ Consumo per capto em 2006 } & \multicolumn{2}{c|}{ Consumo per capto em 2007} \\
\hline & & $\begin{array}{c}\text { Em } \\
\text { casca }\end{array}$ & Produtos & Total & $\begin{array}{c}\text { Em } \\
\text { casca }\end{array}$ & Produtos & Total \\
\hline China & 1,321 & $\mathrm{n} / \mathrm{a}$ & $\mathrm{n} / \mathrm{a}$ & 340 & 286 & 63 & 349 \\
\hline México & 109 & 351 & $\mathrm{n} / \mathrm{a}$ & 351 & 345 & $\mathrm{n} / \mathrm{a}$ & 345 \\
\hline Japão & 127 & 164 & 160 & 324 & 155 & 169 & 323 \\
\hline Dinamarca & 5 & $\mathrm{n} / \mathrm{a}$ & $\mathrm{n} / \mathrm{a}$ & 270 & 174 & 126 & 300 \\
\hline Hungria & 10 & $\mathrm{n} / \mathrm{a}$ & $\mathrm{n} / \mathrm{a}$ & 295 & $\mathrm{n} / \mathrm{a}$ & $\mathrm{n} / \mathrm{a}$ & 295 \\
\hline Ucrânia & 46 & $\mathrm{n} / \mathrm{a}$ & $\mathrm{n} / \mathrm{a}$ & $\mathrm{n} / \mathrm{a}$ & 280 & 11 & 291 \\
\hline USA & 301 & 176 & 80 & 256 & 172 & 78 & 250 \\
\hline França & 63 & $167 \mathrm{t}$ & 84 & 251 & 169 & 76 & 245 \\
\hline Cazaquistão & 10 & 244 & $\mathrm{n} / \mathrm{a}$ & 244 & 244 & $\mathrm{n} / \mathrm{a}$ & 244 \\
\hline Áustria & 9 & $\mathrm{n} / \mathrm{a}$ & $\mathrm{n} / \mathrm{a}$ & 227 & $\mathrm{n} / \mathrm{a}$ & $\mathrm{n} / \mathrm{a}$ & 230 \\
\hline Brasil & 189 & 122 & 10 & 132 & 120 & 12 & 132 \\
\hline
\end{tabular}

Fonte: Adaptado de FAO (2010, p. 49) 
Esse crescente consumo despertou o interesse pela qualidade por parte dos consumidores. Assim, atributos como denominação de origem, rastreabilidade, transparência nos processos produtivos e esquemas de qualidade assegurada vêm ganhando um espaço cada vez maior, conforme Camargo, Barcellos e Malafaia (2008). Estes autores ressaltam ainda, mesmo abordando outra cadeia agroalimentar em seus estudos, itens fundamentais a serem considerados que contemplam conceitos de território, onde se encaixam os aspectos econômicos, políticos, históricos, culturais e sócio-ambientais, para o desenvolvimento de vantagens competitivas.

No Brasil, a produção de ovos está concentrada em São Paulo como maior produtor, seguido por Minas Gerais, Paraná, Rio Grande do Sul e Espírito Santo (UBABEF, 2010, p. 53). Conforme demonstrado na Figura 1, a produção anual de ovos no país teve um comportamento oscilatório. No período entre os anos 2003 e 2007, a produção teve um crescimento, seguido de um declínio entre 2008 e 2010 e voltando a crescer em 2011. Observa-se que o período de declínio da produção de ovos no Brasil coincidiu com a crise financeira mundial.

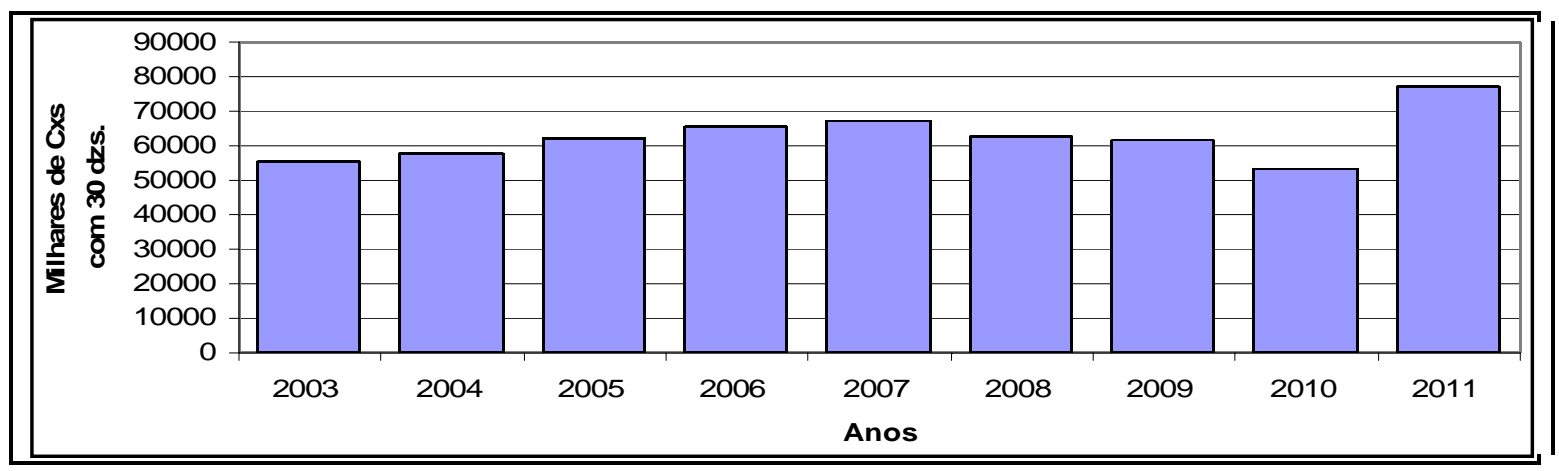

Figura 1 - Produção anual de ovos no Brasil - 2003 a 2011

Fonte: Adaptado de APA (2011)

No cenário mundial a produção de ovos vem apresentando crescimento, conforme Quadro 2, onde observa-se uma variação de $15,12 \%$ no período de 1998 à 2002. Comparando a produção brasileira com a produção mundial no ano de 2002 , verifica-se uma participação de $1,88 \%$, ou seja, ainda pequena, 
ESPÍNDOLA, A.M.S. et al. Avicultura de postura: um estudo de caso através da análise de filière. PUBVET, Londrina, V. 7, N. 3, Ed. 226, Art. 1500, 2013.

mas que expressa à possibilidade da expansão deste mercado para os produtores brasileiros.

Quadro 2 - Produção mundial de ovos, em milhões de unidades

\begin{tabular}{|l|c|c|c|c|c|}
\hline \multicolumn{1}{|c|}{ Países } & $\mathbf{1 9 9 8}$ & $\mathbf{1 9 9 9}$ & $\mathbf{2 0 0 0}$ & $\mathbf{2 0 0 1}$ & $\mathbf{2 0 0 2}$ \\
\hline China & 307,760 & 365,300 & 381,340 & 387,500 & 395,200 \\
\hline União Européia & 89,327 & 88,457 & 85,768 & 88,981 & 89,000 \\
\hline Estados Unidos & 79,896 & 82,943 & 84,420 & 85,812 & 87,240 \\
\hline Japão & 42,117 & 41,975 & 42,041 & 42,100 & 41,900 \\
\hline México & 29,898 & 32,428 & 35,155 & 36,034 & 36,935 \\
\hline Federação Russa & 41,269 & 41,740 & 42,709 & 43,500 & 44,100 \\
\hline Brasil & 13,636 & 14,768 & 14,796 & 15,075 & 15,377 \\
\hline Canadá & 5,986 & 6,151 & 6,597 & 6,700 & 6,780 \\
\hline Outros países & 102,276 & 103,680 & 107,625 & 109,199 & 103,289 \\
\hline Produção mundial & 712,165 & 777,442 & 800,451 & 814,901 & 819,821 \\
\hline \multicolumn{5}{|l|}{ Fonte: Adaptado de APA (2011) } \\
\hline
\end{tabular}

Para os países que tornarem-se aptos a atender suas necessidades de quantidade, a próxima etapa será obter produtos de alta qualidade para satisfazer os consumidores que pedem por produtos seguros e saborosos (MERCIER, 1997). Conforme Nardone e Valfrè (1999), as técnicas de genética (seleção, biologia molecular, transgénese) e as biotecnologias de reprodução desempenham um papel importante na evolução da qualidade, principalmente para as características químico-nutricionais e tecnológicas. Mazzuco (2008) destaca ainda como inovadora tais pesquisas de genoma para a solução dos problemas sanitários e que, também controlam características zootécnicas que interessam a indústria.

\section{MÉTODO}

Este estudo analisou uma empresa fornecedora de aves para avicultura de postura com o objetivo de identificar seus pontos fortes e fracos e posicioná-la na cadeia produtiva, e, para tanto, foi realizada uma entrevista estruturada, pois segundo Lakatos e Marconi (2007, p. 197), a entrevista "é um procedimento utilizado na investigação social, para a coleta de dados ou para ajudar no diagnóstico ou no tratamento de um problema social." A entrevista foi desenvolvida a partir de uma relação fixa de perguntas (GIL, 
2008). A ferramenta utilizada para entrevista foi uma adaptação dos questionários utilizados por Lavalle (1995), Chiarini (1998) e Dantas (2000) para descrever e analisar a organização da logística em empresas brasileiras de diversos segmentos. O questionário consistia de perguntas abertas e fechadas, abordando questões sobre características gerais da empresa, estratégia, complexidade logística, posição no mercado, função na cadeia produtiva e custos.

Logo, essa pesquisa possui uma abordagem qualitativa, com objetivo descritivo, na forma de estudo de caso. A pesquisa qualitativa, conforme Godoy (1995, p. 58), "não procura enumerar e/ou medir os eventos estudados, nem emprega instrumental estatístico", ou seja, parte do foco ou assuntos de relevância vão sendo definidos no transcorrer do estudo. Já uma pesquisa descritiva "observa, registra, analisa e correlaciona fatos ou fenômenos (variáveis) sem manipulá-los." (CERVO; BERVIAN; SILVA, 2007, p. $61)$.

A estratégia de pesquisa adotada foi o estudo de caso, pois, conforme Martins e Theóphilo (2009, p. 62) "trata-se de uma investigação empírica que pesquisa fenômenos dentro do seu contexto real (pesquisa naturalística), onde o pesquisador não tem controle sobre eventos e variáveis." Busca-se aprender o todo de uma situação de forma criativa, descrevendo, compreendendo e interpretando a complexidade de um caso real.

O procedimento técnico utilizado constituiu-se de revisão bibliográfica e da entrevista realizada com um dos sócios-proprietários da empresa. A entrevista foi gravada, sendo posteriormente transcrita. No tratamento de dados foi utilizada a análise de conteúdo, que segundo Vergara (2005, p. 15) "é considerada uma técnica para o tratamento de dados que visa a identificar o que está sendo dito a respeito de determinado tema." Considerou-se este método o mais indicado para identificar na entrevista os pontos fortes e fracos da empresa e posicionar a mesma na cadeia produtiva da avicultura de postura. O desenvolvimento do artigo foi dividido em três etapas. Na primeira etapa foi realizado o planejamento e o cronograma das atividades 
desenvolvidas. A segunda foi composta pela revisão bibliográfica dos conceitos de avicultura de postura, cadeia produtiva, dados estatísticos sobre avicultura e instrumentos de coleta de dados. Por último, foi realizada a entrevista com um dos sócios da empresa estudada.

O objeto de estudo foi uma empresa do setor de avicultura localizada no estado do Rio Grande do Sul, com sede administrativa no município de Porto Alegre, de sociedade limitada. A empresa tem como seu principal produto, o fornecimento de pintos de um dia para o mercado produtor de ovos para consumo.

\section{ESTUDO DE CASO}

A empresa pesquisada foi criada no ano 2000, por ex-funcionários de uma grande empresa do setor de avicultura, que encerrou suas atividades na área de avicultura de postura. A organização possui sessenta funcionários diretos, sendo $10 \%$ em área administrativa e os demais, $90 \%$, subdivididos em técnicos agrícolas e veterinários, além de alguns serviços de apoio terceirizados. O mercado de atuação atende todo o território nacional e exporta regularmente para os Estados Unidos da América, África, Venezuela, Bolívia e Paraguai, atingindo um faturamento aproximado de 18.000.000,00 reais anuais. Sua produção aproximada é de 800 mil pintos mensais, ressaltando que, por tratar-se de avicultura de postura, somente as fêmeas são aproveitadas, sendo os machos eliminados.

As unidades produtivas da empresa estão localizadas nos municípios de Bastos no interior de São Paulo, Urussanga em Santa Catarina e Farroupilha, no Rio Grande do Sul. Comercialmente possui parceiros terceirizados e integrados. Os integrados são pequenas granjas, responsáveis pela recriação das aves, que possuem uma estrutura específica para o crescimento dos pintos (TAUBE-NETTO, 1996). Além disso, a empresa possui uma parceria comercial no estado de Pernambuco, que recebe o ovo fértil, incuba e disponibiliza o 
produto final para os estados do norte e do nordeste do Brasil, atendendo com a agilidade necessária.

Além do pinto de um dia (linhagens Isa Babcock e Lohmann), que é o principal produto, a empresa produz rações para os animais, ovos férteis para a venda direta a outros incubatórios e frangos para recria, que são as frangas prontas para a produção dos ovos. Alguns subprodutos como adubo, galinhas velhas e ovos para o consumo também são vendidos, mas em baixos percentuais.

O prazo médio de entrega dos pintos é de 24 horas após o nascimento, considerando que alguns pedidos possuem condições especiais como vacinas específicas e cortes de crista, que ocorre 3 vezes ao ano. A empresa relacionase de forma cooperativa com seus clientes, que são principalmente de médio porte. As competições de mercado concentram-se, dependendo do momento, em preço, qualidade, prazo e forma de pagamento.

O custo da matéria-prima informada é de $13 \%$ do custo do produto e, segundo o entrevistado, é adequado e está em um bom padrão para ser competitivo no mercado. Uma dificuldade da empresa é a capacidade de ampliação do processo produtivo, visto que toda a cadeia de produção é envolvida e necessita, muitas vezes, de investimentos significativos para abrigar o aumento da produção.

\subsection{Cadeia produtiva da avicultura de postura}

Através da análise de conteúdo efetuada da entrevista com um dos sócios da empresa e das pesquisas bibliográficas realizadas, foi possível desenhar a cadeia produtiva da avicultura de postura, figura 2 , identificando a localização da empresa objeto do estudo e os fluxos existentes com seus fornecedores e clientes, respectivamente.

O processo produtivo da cadeia estudada é cíclico, pois sua etapa produtiva inicia-se com o recebimento do pinto de um dia e termina com a entrega do produto final, sendo este também o pinto de um dia. 
A França e a Holanda são responsáveis pela seleção genética, criação dos bisavós, encaminhando para uma unidade no Brasil, situada em São Paulo, os ovos férteis. A empresa de São Paulo cria os pintos matrizes que são distribuídos por todo país.

O início da cadeia produtiva na empresa estudada ocorre nessa etapa, com o recebimento dos pintos de 1 dia oriundos de São Paulo. Esses pintos são criados até a $6^{\mathrm{a}}$ semana, incluindo a vacina, a alimentação e o manejo. $\mathrm{Na} 7^{\mathrm{a}}$ semana são enviados para os integrados. Os ovos produzidos são coletados e armazenados, conforme as exigências técnicas, pelos próprios integrados. A empresa é responsável pela coleta, em todos os integrados, dos ovos férteis produzidos. Observa-se que a logística é fundamental nesse processo, ressaltando-se que os caminhões utilizados são próprios da organização. Atualmente existem 120 mil matrizes distribuídas nos integrados.

Os ovos férteis são então encubados em outra unidade produtiva da empresa até que os pintos nasçam. Após o nascimento, a organização possui até 48 horas para fazer a distribuição do produto final (pinto de 1 dia). Estes passam por uma seleção, vacinação e algum tratamento específico, caso solicitado pelo cliente, até ser embalado para o transporte, também realizado por frota própria da empresa, que atende todo o território nacional. O transporte rodoviário é realizado até os estados do Espírito Santo, Minas Gerais e Goiás. Uma empresa terceirizada, que se encontra em Pernambuco, é responsável pela distribuição dos pintos de 1 dia nos estados da região nordeste do país. Esse terceiro possui um encubatório e realiza as etapas finais do processo produtivo em sua unidade. A distribuição nos demais estados, região norte e parte do centro-oeste, é realizada via aéreo. Do total da produção de pintos de 1 dia, que geram cerca de 10 milhões de reais mensais, $15 \%$ é destinado para exportação, sendo enviada via rodoviário ao Paraguai e via aéreo aos demais países.

Os clientes da empresa recebem o pinto de 1 dia e o ciclo de produção se repete, através de manejo, alimentação e vacina, lembrando que os ovos por eles produzidos são os ovos comercializados nos mercados e consumidos pela 
ESPÍNDOLA, A.M.S. et al. Avicultura de postura: um estudo de caso através da análise de filière. PUBVET, Londrina, V. 7, N. 3, Ed. 226, Art. 1500, 2013.

população. Salienta-se que na cadeia produtiva da avicultura de postura existem subprodutos gerados como adubo, ovo comercial (início da vida produtiva das galinhas) e a galinha velha.

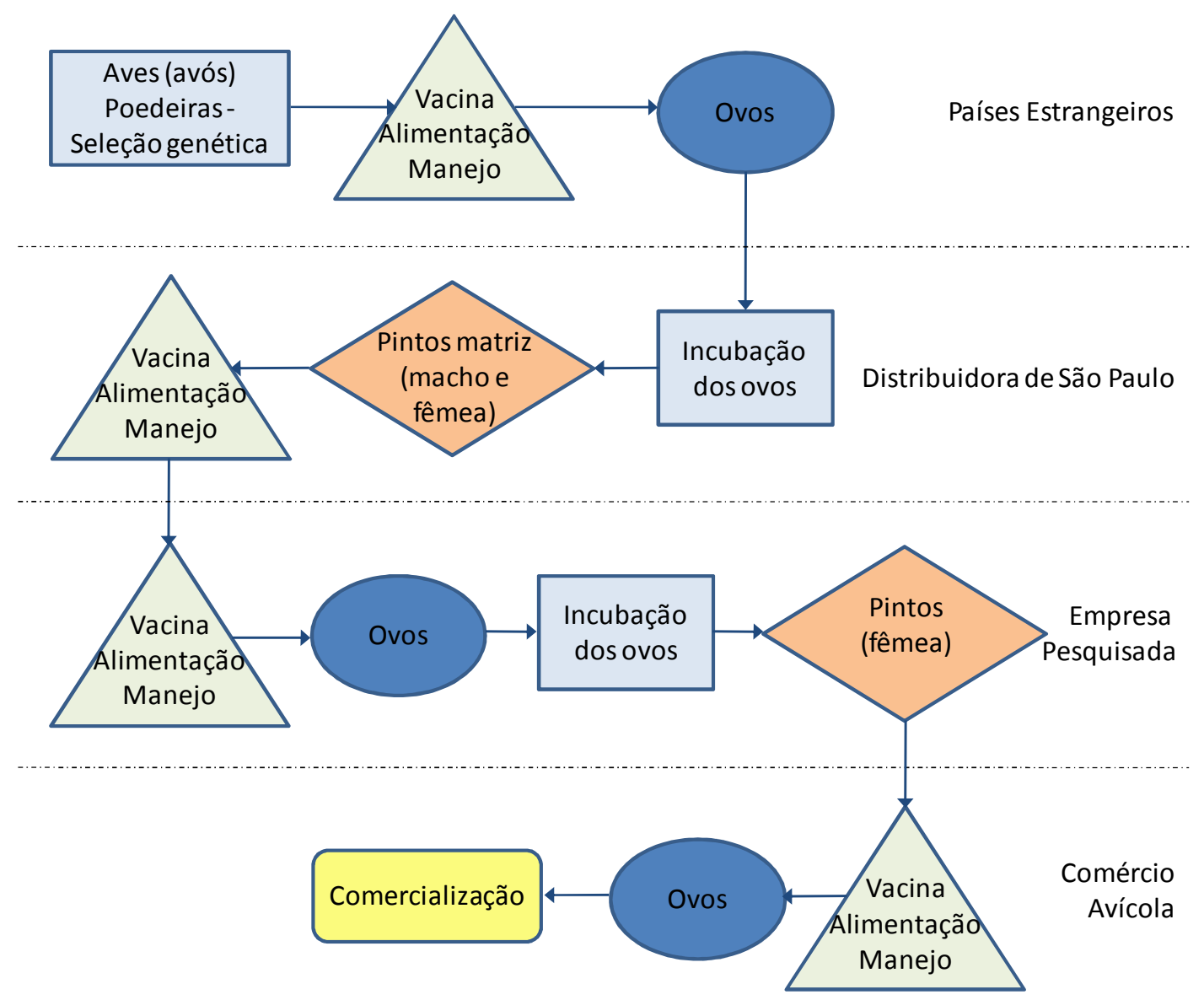

Figura 2 - Cadeia produtiva da avicultura de postura

Fonte: Elaborado pelos autores com base na entrevista e nas pesquisas bibliográficas realizadas

O maior gargalo do processo produtivo ocorre no consumo final do mercado, ou seja, com os consumidores de ovos. A matéria-prima de alimentação das aves (milho e soja) também aparece como sendo um gargalo e, com menor intensidade, o transporte aéreo, pois pode comprometer todo o lote produzido. 
Considerando o processo produtivo total, figura 2, a demora para fechamento do ciclo ocorre em aproximadamente 2 anos, pois a Distribuidora de São Paulo necessita de 7 meses até fornecer os pintos matrizes, a empresa pesquisada necessita de mais 7 meses até estar apta a fornecer os pintos fêmeas e o comércio avícola ocupa 6 meses até produzir ovos para comercialização. Considerando 4 meses para o processo nos países estrangeiros, totaliza em 24 meses o tempo necessário para que os ovos de consumo estejam sendo comercializados.

\subsection{Análise filière}

A análise de filière é uma análise de como as lógicas dos agentes, dos produtos e dos mercados se articulam entre si para estruturar um sistema. Seu comprimento pode variar de acordo com a natureza do produto analisado, do ponto central adotado ou do estágio dos processos de integração vertical (MALAFAIA, 2011).

Para facilitar o entendimento, optou-se por desenhar, através da abordagem filière, o encadeamento das operações técnicas necessárias até a elaboração do produto final da empresa pesquisa, buscando identificar as atividades principais que regem a produção da organização. O objetivo desta análise foi apresentar uma modalidade de recorte do sistema produtivo, permitindo referir as empresas e os ramos que têm relações de compra e venda intensas entre si e com isso, identificar os pontos fortes e fracos existentes na organização pesquisada. A figura 3 demonstra o recorte realizado para a análise filière.

As atividades de apoio que impactam na cadeia produtiva foram identificadas como sendo:

as políticas públicas;

o sistema financeiro;

a inspeção sanitária; 
as políticas de comércio exterior;

as políticas de renda.

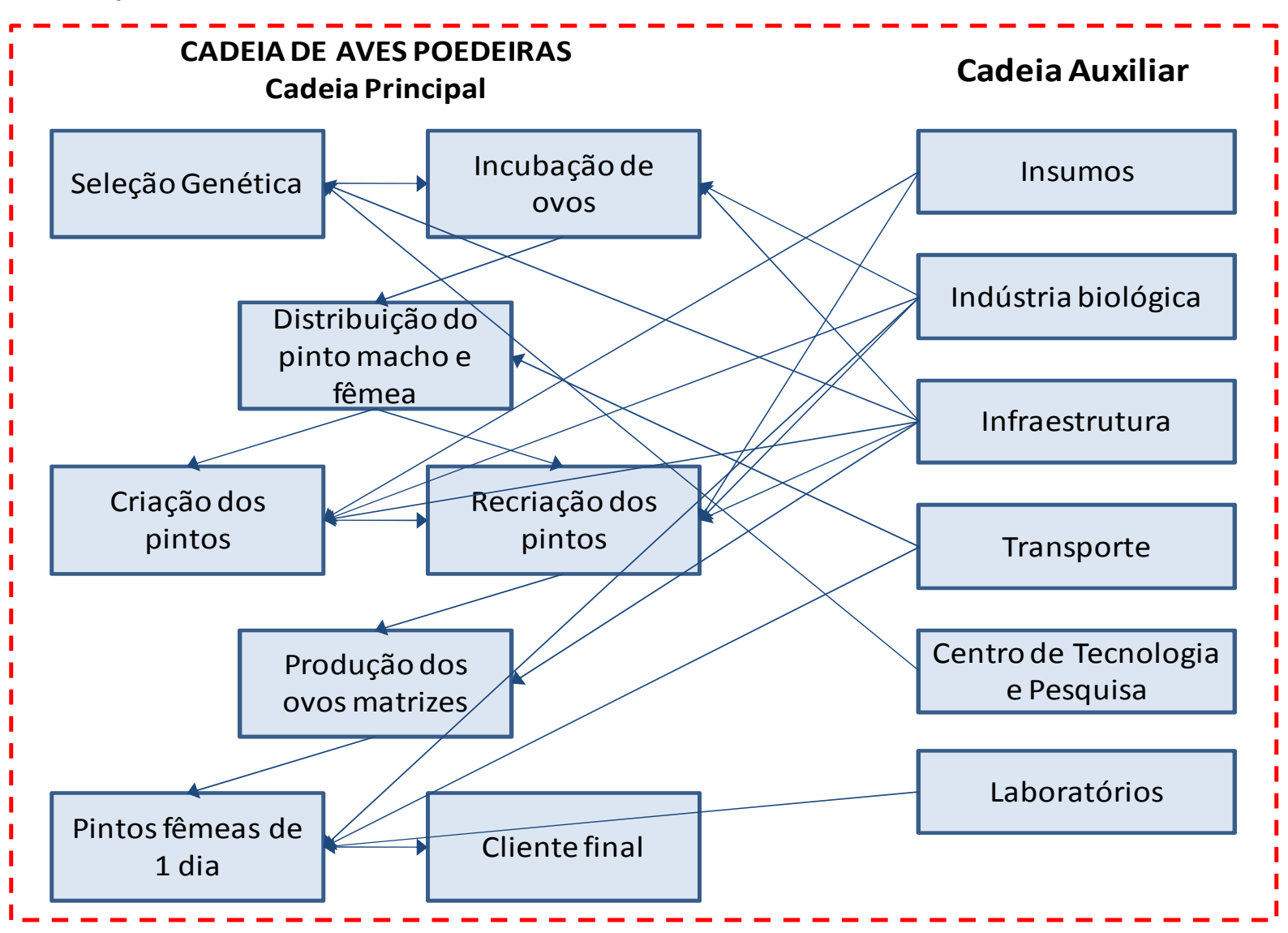

Figura 3 - Cadeia das aves poedeiras

Fonte: Elaborado pelos autores com base na entrevista realizada

\section{RESULTADOS E CONSIDERAÇÕES FINAIS}

$O$ estudo de caso teve por objetivo identificar os pontos fortes e fracos da empresa fornecedora de aves para avicultura de postura através da análise filière. Através das análises efetuadas, identificou-se como pontos fortes da empresa os seguintes itens:

a) logística própria: por se tratar de um produto que possui o tempo de entrega como gargalo no processo produtivo, a logística torna-se fundamental para cumprir com o desempenho organizacional; 
b) fornecimento de insumos: a localização da empresa permite que o recebimento de insumos necessários ao seu processo de produção seja facilitado;

c) serviços agregados: a organização possui uma estrutura descentralizada que permite o atendimento das solicitações especiais de seus clientes;

d) relações com os clientes: possui uma relação de cooperação com os seus clientes, garantindo que sejam próximas e contínuas.

E, os pontos fracos foram identificados como sendo:

a) mão de obra: a falta de pessoal com estrutura própria e qualificada para trabalhar como agregado dificulta a expansão da empresa;

b) fornecedor da matéria-prima: dependência de um único fornecedor, que atende todo o território nacional, dominando a tecnologia e dificultando o aumento da capacidade produtiva da empresa, uma vez que possui uma programação rígida, firmada em contrato, para entrega de seus produtos.

A cadeia produtiva estudada possui uma estrutura bem definida, podendo ser aprimorada com mais investimentos na solução dos gargalos existentes. O mercado consumidor, matéria-prima de alimentação, matériaprima de matrizes e logística são os principais gargalos da cadeia. As soluções para estes devem ser pensadas de forma integrada, pois existe um encadeamento ordenado entre eles. Não adianta fazer uma campanha de incentivo ao consumo de ovos se a produção fica dependendo do fornecimento das aves matrizes, de alimentação e de uma estrutura rodoviária e aérea para distribuição da produção. É importante destacar que as soluções para os gargalos passam também pelas políticas públicas, sistema financeiro, políticas de comércio exterior, inspeção sanitária e pesquisa e desenvolvimento na seleção genética. 
ESPÍNDOLA, A.M.S. et al. Avicultura de postura: um estudo de caso através da análise de filière. PUBVET, Londrina, V. 7, N. 3, Ed. 226, Art. 1500, 2013.

Dito isto, ressalta-se que fatores como crescimento populacional, mudanças nas estruturas sociais e exigências de quantidade e qualidade pelo mercado consumidor, requerem uma capacidade de inovação e adaptação das cadeias produtivas, e em especial das cadeias produtivas de alimentos. Estes fatores justificam importância de se conhecer a estrutura da cadeia produtiva da avicultura de postura, pois somente com estudos sobre esta, poderemos formalizar o conhecimento existente, identificar os pontos positivos, os problemas e sugerir melhorias para que a cadeia seja aprimorada e supra as necessidades do mercado em expansão.

A limitação da pesquisa está associada à única visão analisada, do sócio da empresa, por tratar-se de um estudo de caso. Contudo, essa limitação resulta numa oportunidade para estudos futuros, buscando investigar as características de outras empresas nesse segmento e comparar as semelhanças e diferenças existentes; para então sugerir melhorias que atendam as necessidades da cadeia como um todo.

\section{REFERÊNCIAS}

APA - Associação Paulista para Avicultura. Estatísticas. Disponível em:

<http://www.apa.com.br/apa_estatisticas.php>. Acesso em: 19 dez. 2011.

BANDT, J. Les filières de production: mythe ou réalité? Economie et PME, n. 3, décembre, 1982.

BATALHA, M. O. et al. Gestão agroindustrial. São Paulo, Atlas, 1997. 2 v.

Gestão agroindustrial. 3. ed. São Paulo: Atlas, 2001. 2 v.

BOOMGARD, J. J.; DAVIES, S. P.; HAGGBLADE, S. J.; MEAD, D. C. A subsector approach to small enterprise promotion and research. World Development, v. 19, n. 3, p. 199-212, 1991.

CAMARGO, M. E.; BARCELLOS, J. O. J.; MALAFAIA, G. C. As convenções sociais de qualidade criadas em sistemas agroalimentares locais: o caso da indicação de procedência da carne do pampa gaúcho, ENANPAD, 2008.

CERVO, A. L.; BERVIAN, P. A.; SILVA, R. Metodologia científica. 6. ed. São Paulo: Pearson Prentice Hall, 2007.

CHIARINI, A. B. A organização logística em empresas brasileiras que apresentam as melhores práticas de níveis de serviço: estudo de caso. 1998. 144 f. Dissertação (Mestrado em Administração) - COPPEAD, Universidade Federal do Rio de Janeiro, Rio de Janeiro, 1998. 
DANTAS, E. M. de A. Estágio da organização logística de três empresas do setor de bebidas: um estudo de caso. 2000. 136 f. Dissertação (Mestrado em Administração) COPPEAD, Universidade Federal do Rio de Janeiro, Rio de Janeiro, 2000.

FAO - Organização das Nações Unidas para Agricultura e Alimentação. Agribusiness handbook: poultry meat e eggs. Itália: 2010. Disponível em:

<http://www.fao.org/docrep/012/al175e/al175e.pdf>. Acesso em: 30 fev. 2012.

FLORIOT, J. L. Pratique de I'analyse filière et génie des systèmes industriels. Paris: Editions Economica, 1985.

GIL, A. C. Métodos e técnicas de pesquisa social. 6. ed. São Paulo: Atlas, 2008.

GODOY, A. S. Introdução à pesquisa qualitativa e sua possibilidades: uma revisão histórica dos principais autores e obras que refletem esta metodologia de pesquisa em ciências sociais.

Revista de Administração de Empresas, v. 35, n. 2, p. 57-63, mar./abr., 1995.

LAKATOS, E. M.; MARCONI, M. A. Metodologia científica. 5. ed. rev. e ampl. São Paulo: Atlas, 2007.

LAURET, F. Sur les etudes de filieres agro-alimentaire. Economies et Societes, Série AG, n. 17, p. 721-740, 1983.

LAVALLE, C. R. S. O estágio de desenvolvimento da organização logística em empresas brasileiras: estudo de caso. 1995. 277 f. Dissertação (Mestrado em Administração) COPPEAD, Universidade Federal do Rio de Janeiro, Rio de Janeiro, 1995.

MALAFAIA, G. C. Análise de filière: cadeia produtiva agroindustrial. Apresentação..., 2011.

MANNING, L.; BAINES, R. N.; CHADD, S. A. Quality assurance: a study of the primary poultry producers' perspective. British Food Journal, v. 109, n. 4, p. 291-304, 2007.

MARTINS, G. A.; THEÓPHILO, C. R. Metodologia da investigação científica para ciências sociais aplicadas. 2. ed. São Paulo: Atlas, 2009.

MAZZUCO, H. Ações sustentáveis na produção de ovos. Revista Brasileira de Zootecnia, v. 37, suplemento especial, p. 230-238, 2008.

MERCIER, C. La stratègie industrielle. Proc. 50 ans de recherches à I'INRA, La Recherche Agronomique Européenne dans le monde du 21 siècle, Strasbourg, 28-29 Settembre, 1997.

MIZUMOTO, C. N. A comunicação empresarial na avicultura de postura: Brasil e Argentina, uma análise comparada. 1996. 154 f. Dissertação (Mestrado em Administração). Universidade de São Paulo, São Paulo, 1996.

MORVAN, Y. Filière de production: fondaments d'economie industrielle. 2. ed. Paris: Economica, 1985.

Fondements d'économie industrielle. Paris: Economica, 1988.

NARDONE, A.; VALFRÈ, F. Effects of changing production methods on quality of meat, milk and eggs. Livestock Production Science, v. 59, p. 165-182, 1999.

NERI, M. C. (Coord.). A nova classe média. Rio de Janeiro: FGV/IBRE, 2008. Disponível em: <http://www3.fgv.br/ibrecps/M3/M3_ANovaClasseMedia_Port_2.pdf>. Acesso em: 04 abr.

2012.

OASHI, M. C. G. Estudo da cadeia produtiva como subsídio para pesquisa e desenvolvimento do agronegócio do SISAL na Paraíba. Tese (Doutorado em Engenharia de Produção). Universidade Federal de Santa Catarina, Santa Catarina, Florianópolis, 1999.

PEDROZO, A. A.; FRANCISCO, D. C. A importância da gestão da informação entre os elos da cadeia produtiva de frangos. Sociedade Brasileira de Economia, Administração e 
Sociologia Rural - SOBER, Cuiabá, 2004. Disponível em:

<http://www.sober.org.br/palestra/12/020086.pdf>. Acesso em: 06 mar. 2012.

SHAFFER, J. D. On the concept of subsector studies. American Journal of Agricultural Economics, v. 55, n. 2, p. 333-335, 1973.

SOBRINHO, J. K.; FONSECA, R. A. Análise econômica da produção de ovos de galinhas poedeiras no município de Toledo (PR). Revista Eletrônica Lato Sensu, ano 2 , n. 1, p. 1-20, jul. 2007.

SOSSIDOU, E. N.; ELSON, H. A. Hens' welfare to egg quality: a European perspective.

World's Poultry Science Journal, v. 65, p. 709-718, December, 2009.

TAUBE-NETTO, M. Integrated planning four poultry production at Sadia. Interfaces, v. $26, \mathrm{n}$. 1, p. 38-53, Jan./Feb. 1996.

UBABEF - União Brasileira de Avicultura. Relatório anual. Brasil: 2010/2011. Disponível em: <http://www.abef.com.br/ubabef/exibenoticiaubabef.php?notcodigo=2761>. Acesso em: 21 dez. 2011.

VERGARA, S. C. Métodos de pesquisa em administração. São Paulo: Atlas, 2005. 